\title{
Tratamento farmacológico através da utilização da glicose para fins terapêuticos em feridas agudas e crônicas: revisão integrativa
}

\begin{abstract}
A glicose é um tipo de solução estéril e aspirogênicas usadas no estabelecimento de fluidos e suprimento calórico. 0 trabalho tem como objetivo demonstrar a importância do uso de glicose no tratamento de feridas complexas, sendo estas agudas ou crônicas, quando comparados a outros tipos de fármacos, como o alginato de cálcio, hidrofibras, hidrocolóides, entre outros. Trata-se de uma pesquisa bibliográfica do tipo revisão integrativa, em que foram selecionadas algumas bases de dados para serem utilizados para a busca, que foram: Scientific Eletronic Library Online (SCIELO), e na Literatura Latino-Americana e do Caribe em Ciências da Saúde (LILACS) e Base de Dados da Enfermagem (BDENF). Os estudos apresentados evidenciam a eficácia da utilização da glicose tanto na sua forma in natura quanto também na forma de mel processado e esterilizado (industrializado) especialmente para o uso no tratamento de feridas, no processo de reparo do tecido lesado bem como no tratamento da infecção. A utilização da glicose reduz o tempo de cicatrização ofertando vários benefícios clínicos em que houve a comparação com mel a base de glicose da classe médica com tratamentos convencionais sobre as taxas de cura de feridas de cicatrização por segunda intenção. A combinação da glicose juntamente com o mel Ulmo e ácido ascórbico apresentaram excelentes resultados, com cura das feridas em $100 \%$ dos pacientes com todos os tipos de úlceras venosas, com média de 37 dias de recuperação, que é rápido, quando comparado com o tempo registrado para tratamentos convencionais. 0 uso dessa prática medicinal no tratamento de feridas apresenta vários efeitos satisfatórios, entretanto há necessidade de mais estudos para garantir uma prática mais segura.
\end{abstract}

Palavras-chave: Glicose; Tratamento de Feridas; Processo de Cicatrização.

\section{Pharmacological treatment through the use of glucose for therapeutic purposes in acute and chronic wounds: integrative}

\section{review}

\begin{abstract}
Glucose is a type of sterile and aspirogenic solution used in fluid establishment and caloric supply. This study aims to demonstrate the importance of using glucose in the treatment of complex wounds, whether acute or chronic, when compared to other types of drugs, such as calcium alginate, hydrofibers, hydrocolloids, among others. This is a bibliographic research of the integrative review type, in which some databases were selected to be used for the search, which were: Scientific Electronic Library Online (SCIELO), and the Latin American and Caribbean Literature on Health (LILACS) and Nursing Database (BDENF). The studies presented show the efficacy of using glucose both in its in natura form and in the form of processed and sterilized (industrialized) honey especially for use in wound care, in the repair process of injured tissue as well as in the treatment of glucose. infection. Glucose utilization reduces healing time by offering several clinical benefits compared to medical grade honey with conventional treatments on healing rates of secondary intention healing wounds. The combination of glucose along with Ulmo honey and ascorbic acid showed excellent results, with wound healing in $100 \%$ of patients with all types of venous ulcers, with an average recovery time of 37 days, which is fast compared to time. registered for conventional treatments. The use of this medicinal practice in the treatment of wounds has several satisfactory effects, but further studies are needed to ensure a safer practice.
\end{abstract}

Keywords: Glucose; Wound care; Healing process.

Topic: Controle de Fármacos e Medicamentos

Reviewed anonymously in the process of blind peer

Wellington Pereira Rodrigues (iD

Centro Universitário AGES, Brasil

http://lattes.cnpq.br/2798105983752891

http://orcid.org/0000-0002-0993-6871

wellington life@live.com

Priscila Dantas Gonçalves (iD

Centro Universitário AGES, Brasil

http://lattes.cnpq.br/7078066094809493

http://orcid.org/0000-0002-1849-0226

prisciladantasg@hotmail.com

Renan Sallazar Ferreira Pereira (iD)

Universidade Federal do Amazonas, Brasil

http://lattes.cnpq.br/8154326371029706

http://orcid.org/0000-0001-5140-4046

renansallazar@gmail.com

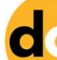

DOI: 10.6008/CBPC2236-9600.2019.001.0005
Received: 12/11/2018

Approved: 14/01/2019

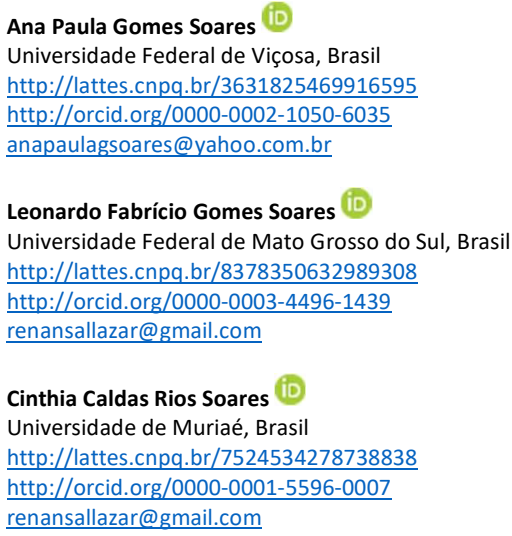

\section{Referencing this:}

RODRIGUES, W. P.; GONÇALVES, P. D.; PEREIRA, R. S. F.; SOARES, A. P. G.; SOARES, L. F. G.; SOARES, C. C. R.. Tratamento farmacológico através da utilização da glicose para fins terapêuticos em feridas agudas e crônicas: revisão integrativa. Scire Salutis, v.9, n.1, p.37-42, 2019. DOI: http://doi.org/10.6008/CBPC2236-9600.2019.001.0005 


\section{INTRODUÇÃO}

A ferida pode ser denominada como uma complicação biológica, que tende a regredir espontaneamente e completamente (cicatrização) dentro de um prazo mais ou menos pré-estabelecido, onde pode ocorrer algumas variações individuais. Porém podem surgir complicações que retardam a cicatrização, como a infecção, que prolonga a convalescença, aumentando os custos do tratamento (ANDRADE et al., 2014).

A glicose é um tipo de solução estéril e aspirogênica usada no estabelecimento de fluidos e suprimento calórico. Balizado por estar ideia, este fármaco é um nutriente facilmente metabolizado pelo organismo para fornecimento de energia, dispensando em alguns casos o uso de lipídeos e proteínas como fontes de energia, evitando, assim, acidose e cetose resultantes de seus metabolismos. A solução de glicose é útil como fonte de água e calorias e é capaz de induzir diurese dependendo das condições clínicas do paciente, quando utilizado em concentrações isotônicas, são adequadas para a manutenção das necessidades de água, neste caso aumentando a eficácia na hidratação de feridas complexas (MORTON, 2014).

O tratamento de feridas infectadas constitui um grande desafio da prática de enfermagem e médica. Vários estudos confirmaram as propriedades particulares da glicose, com resultados positivos na cicatrização de feridas e lesões não cicatrizantes, atribuindo-se tais eventos progressivos cicatriciais às propriedades específicas do mel como a elevada viscosidade e osmolaridade e seu conteúdo nutritivo, contribuindo com a inibição do crescimento bacteriano e promovendo a cicatrização das feridas. A utilização da glicose no tratamento de feridas reside nas suas propriedades antimicrobianas, sendo cada vez maior o número de pesquisas na área (PHILLIPS, 2016).

O trabalho tem como objetivo demonstrar a importância do uso de glicose no tratamento de feridas complexas, sendo estas agudas ou crônicas, quando comparados a outros tipos de fármacos, como o alginato de cálcio, hidrofibras, hidrocolóides, entre outros. Deve-se considerar, para fins de administração, dados clínicos e laboratoriais, como níveis glicêmicos e glicosúria (excesso de glicose na urina), assim, faz-se necessário a monitoração frequente de concentrações de glicose, de eletrólitos particularmente de potássio no plasma para evitar maiores imprevistos.

A glicose atua na atividade inflamatória, reduzindo o edema, quimiotaxia de macrófagos através da liberação de sinais bioquímicos, proliferação de angioblastos e fibroblastos e atividade antimicrobiana, devido a liberação do peróxido de hidrogênio a partir da glicose, presença de inibina, capacidade higroscópia e pH baixo (SMELTZER, 2014).

\section{MATERIAIS E MÉTODOS}

Trata-se de uma pesquisa bibliográfica do tipo revisão integrativa, em que foram selecionadas algumas bases de dados para serem utilizados para a busca, que foram: Scientific Eletronic Library Online 
(SCIELO) e na Literatura Latino-Americana e do Caribe em Ciências da Saúde (LILACS) e Base de Dados da Enfermagem (BDENF).

Em seguida foram utilizados os seguintes critérios de inclusão dos estudos: textos completos, estudos primários, realizados no período de 2009 a 2017, com humanos, nos idiomas português e espanhol. Depois foi realizada leitura analítica dos títulos e resumos e toda a bibliografia selecionada para ordenar as informações e identificar os objetos de estudo. Passo seguinte foi leitura exploratória e interpretativa das publicações, com a finalidade de ressaltar as principais ideias consideradas para essa revisão.

Para extração dos dados, elaborou-se e adotou-se um instrumento contemplando as variáveis: procedência, título do artigo, autores, ano, tipo de estudo e temática. As temáticas foram agrupadas conforme semelhança de conteúdo para serem discutidas em seguida. Ao todo foram selecionados 7 artigos para análise.

\section{RESULTADOS E DISCUSSÃO}

O uso do açúcar nas feridas pode parecer a princípio uma panaceia, porém não é. Os demais cuidados com as feridas deverão ser tomados quando necessários, como boa manutenção da irrigação sanguínea, desbridamento e hemostasia para obtenção de bons resultados. Há muitas pesquisas que tentam explicar o efeito do açúcar sobre feridas. Experiências em laboratório evidenciaram que é um antimicrobiano, inibindo o crescimento de bactérias gram positivas e gram negativas. Parece que tem a mesma ação na superfície das feridas infectadas.

Tabela 1: Distribuição dos artigos selecionados segundos os meios eletrônicos em 2018.

\begin{tabular}{|c|c|c|c|c|c|c|}
\hline Bases de dados & Título & Autores & $\begin{array}{c}\text { Ano de } \\
\text { publicação }\end{array}$ & $\begin{array}{l}\text { Método } \\
\text { aplicado }\end{array}$ & País & Resultados \\
\hline $\begin{array}{l}\text { MEDLINE - } \\
\text { Instituto } \\
\text { Politécnico de } \\
\text { Viseu: Escola } \\
\text { Superior de } \\
\text { Saúde de Viseu }\end{array}$ & $\begin{array}{l}\text { A aplicação tópica de } \\
\text { glicose no tratamento } \\
\text { de feridas infetadas: } \\
\text { revisão sistemática da } \\
\text { literatura. }\end{array}$ & $\begin{array}{c}\text { SANTOS, C. A. } \\
\text { A. }\end{array}$ & 2015 & $\begin{array}{l}\text { Revisão } \\
\text { Sistemática da } \\
\text { Literatura. }\end{array}$ & Brasil & $\begin{array}{l}\text { No nosso país assistiu-se, nos } \\
\text { últimos anos, um pouco por todos } \\
\text { os contextos de cuidados, à grande } \\
\text { utilização de materiais tópicos } \\
\text { impregnados com glicose no } \\
\text { tratamento de feridas agudas e } \\
\text { crónicas, muitas vezes mesmo sem } \\
\text { se verificar a presença de infeção. }\end{array}$ \\
\hline $\begin{array}{l}\text { LILACS - } \\
\text { Universidade } \\
\text { Federal de } \\
\text { Uberlândia } \\
\text { faculdade de } \\
\text { medicina: } \\
\text { Programa de } \\
\text { pós-graduação } \\
\text { em ciências da } \\
\text { saúde }\end{array}$ & $\begin{array}{l}\text { Comparar um mel a } \\
\text { base de glicose da } \\
\text { classe médica com } \\
\text { tratamentos } \\
\text { convencionais sobre } \\
\text { as taxas de cura de } \\
\text { feridas de cicatrização } \\
\text { por segunda intenção. }\end{array}$ & $\begin{array}{l}\text { ROBSON, V; } \\
\text { DODD, S; } \\
\text { THOMAS, S. }\end{array}$ & 2009 & $\begin{array}{l}\text { Ensaio Clínico } \\
\text { Controlado } \\
\text { Aleatório Nível } \\
\text { II. }\end{array}$ & Brasil & $\begin{array}{l}\text { O tempo médio de cicatrização no } \\
\text { grupo mel foi de } 100 \text { dias, em } \\
\text { comparação com } 140 \text { dias no grupo } \\
\text { controle }\end{array}$ \\
\hline $\begin{array}{l}\text { LILACS - Revista } \\
\text { Brasileira de } \\
\text { Cirurgia Plástica }\end{array}$ & $\begin{array}{l}\text { Relatar o tempo } \\
\text { médio de cicatrização } \\
\text { de feridas oncológicas } \\
\text { após excisão tratadas } \\
\text { com a aplicação de } \\
\text { uma formulação } \\
\text { contendo própolis, } \\
\text { mel, açúcar, manteiga } \\
\text { e albumina em pó. }\end{array}$ & $\begin{array}{l}\text { PEREIRA FILHO, } \\
\text { J. S; BICALHO, L; } \\
\text { SILVA, DA. }\end{array}$ & 2012 & $\begin{array}{c}\text { Analítico Nível } \\
\text { V. }\end{array}$ & Brasil & $\begin{array}{l}\text { O tempo de cicatrização médio foi } \\
\text { equivalente a } 39 \text { dias e a região } \\
\text { anatômica na qual foi observada } \\
\text { maior prevalência de lesões } \\
\text { associadas ao câncer de pele foi a } \\
\text { cabeça. }\end{array}$ \\
\hline $\begin{array}{c}\text { PUBMED - } \\
\text { Universidade } \\
\text { Federal de Santa } \\
\text { Catarina }\end{array}$ & $\begin{array}{l}\text { Cartilha de curativo } \\
\text { especial: projeto de } \\
\text { intervenção equipe de } \\
\text { saúde unidade de } \\
\text { saúde Abaeté. }\end{array}$ & $\begin{array}{c}\text { COSTA. H, M, L, } \\
\text { M. }\end{array}$ & 2014 & $\begin{array}{c}\text { Pesquisa } \\
\text { Bibliográfica. }\end{array}$ & Brasil & $\begin{array}{l}\text { O tratamento das feridas inclui } \\
\text { métodos clínicos e cirúrgicos. O } \\
\text { curativo é o tratamento clínico mais } \\
\text { frequentemente utilizado. A } \\
\text { escolha do material adequado para }\end{array}$ \\
\hline
\end{tabular}




\begin{tabular}{|c|c|c|c|c|c|c|}
\hline & & & & & & $\begin{array}{l}\text { o curativo decorre do } \\
\text { conhecimento fisiopatológico e } \\
\text { bioquímico da reparação tecidual, } \\
\text { representadas não apenas pela } \\
\text { ruptura da pele e do tecido celular } \\
\text { subcutâneo, mas também, em } \\
\text { alguns casos músculos, tendões e } \\
\text { ossos. }\end{array}$ \\
\hline $\begin{array}{l}\text { PUBMED - } \\
\text { Sociedade } \\
\text { Brasileira de } \\
\text { Dermatologia } \\
\text { Brasil }\end{array}$ & $\begin{array}{l}\text { Investigar o efeito de } \\
\text { curativos impregnados } \\
\text { com mel manuka } \\
\text { (MHID) com glicose na } \\
\text { cicatrização de úlceras } \\
\text { do pé diabético } \\
\text { neuropática (NDFU) }\end{array}$ & $\begin{array}{l}\text { KAMARATOS } \\
\text { AVET, A. L. }\end{array}$ & 2014 & Descritivo. & Brasil & $\begin{array}{l}\text { O mel manuka representa um } \\
\text { tratamento eficaz para a } \\
\text { cicatrização de úlceras do pé } \\
\text { diabético neuropática, levando a } \\
\text { uma redução significativa no tempo } \\
\text { de cura rápida e desinfecção de } \\
\text { úlceras. }\end{array}$ \\
\hline $\begin{array}{l}\text { MEDLINE - } \\
\text { Revista Brasileira } \\
\text { de Queimaduras. }\end{array}$ & $\begin{array}{l}\text { Avaliar o efeito clínico } \\
\text { de tratamento tópico } \\
\text { com mel de Ulmo } \\
\text { associado à glicose } \\
\text { administração oral de } \\
\text { ácido ascórbico em } \\
\text { pacientes portadores } \\
\text { de úlceras venosas. }\end{array}$ & $\begin{array}{l}\text { CALDERON, M. } \\
\text { S; FIGUEROA, C. } \\
\text { S; ARIAS, J. S; } \\
\text { SANDOVAL, A. } \\
\text { H; TORRE, F. O. }\end{array}$ & 2015 & $\begin{array}{l}\text { Estudo } \\
\text { quantitativo } \\
\text { descritivo } \\
\text { longitudinal. } \\
\text { Nível V. }\end{array}$ & Brasil & $\begin{array}{c}\text { Cicatrização completa foi observada } \\
\text { em } 100 \% \text { das úlceras venosas. Não } \\
\text { foram observados sinais de } \\
\text { complicação tais como alergias ou } \\
\text { infecção. }\end{array}$ \\
\hline $\begin{array}{l}\text { MEDLINE - } \\
\text { Revista Brasileira } \\
\text { de Queimaduras }\end{array}$ & $\begin{array}{l}\text { O USO DO AÇÚCAR } \\
\text { NAS FERIDAS } \\
\text { INFECTADAS }\end{array}$ & $\begin{array}{l}\text { HAHHAD, M. C. } \\
\text { L; VANNUCHI, } \\
\text { M. T. O; } \\
\text { CHENSO, M. Z. } \\
\text { B; HAULY, M. C } \\
\text { de O. }\end{array}$ & 2017 & $\begin{array}{l}\text { Estudo } \\
\text { quantitativo } \\
\text { descritivo } \\
\text { exploratório. }\end{array}$ & Brasil & $\begin{array}{l}\text { Os resultados também foram } \\
\text { positivos para doentes portadores } \\
\text { de diabetes, sem qualquer efeito } \\
\text { colateral, o que coincide com } \\
\text { relatos de alguns autores. Pode ser } \\
\text { utilizado em doentes graves e em } \\
\text { diabéticos sem complicações por } \\
\text { ser uma substância inodora, indolor } \\
\text { e não irritante. }\end{array}$ \\
\hline
\end{tabular}

Os estudos apresentados evidenciam a eficácia da utilização da glicose tanto na sua forma in natura, quanto também na forma de mel processado e esterilizado (industrializado) especialmente para o uso no tratamento de feridas, no processo de reparo do tecido lesado bem como no tratamento da infeç̧ão (HAHHAD et al., 2017). Isto tem sido visto de maneira positiva, uma vez que seu uso pode significar uma diminuição significativa nos custos do tratamento. Como pode ser visto nos quadros sinópticos, a glicose tem sido estudada em situações diversas.

Com o aumento da expectativa de vida das pessoas, as causas externas vêm ganhando cada vez mais destaque na transição epidemiológica, sendo a população jovem e economicamente ativa a mais afetada, originando grandes impactos sociais ao poder público. Tal fato faz com que este público possua feridas graves, de tratamento complexo e prolongando, contribuindo para a elevação dos custos hospitalares. A alta prevalência de vítimas de trauma faz com que cresça a frequência de feridas de difícil cicatrização, demandando não somente maior atenção de médicos e enfermeiros, mas, também dos administradores preocupados com os custos da terapêutica (KAMARATOS et al., 2014).

A utilização da glicose reduz o tempo de cicatrização ofertando vários benefícios clínicos conforme aponta Robson, Dodd e Thomas, em seu estudo, que comparou um mel a base de glicose da classe médica com tratamentos convencionais sobre as taxas de cura de feridas de cicatrização por segunda intenção, o grupo de pacientes que utilizaram o mel a base de glicose em seu tratamento teve a cicatrização completa em média de 100 dias, já o grupo controle, que foi submetido ao tratamento convencional levaram 140 dias para cicatrizar as lesões. Entretanto os autores apontam a necessidades de mais pesquisas (PEREIRA FILHO, 2012). 
Em uma pesquisa realizada no interior de São Paulo sobre o manejo de feridas neoplásicas, os autores identificaram que as coberturas utilizadas com maior frequência para tratamento, foram sulfadiazina de prata e ácido graxo essencial (AGE), produtos não recomendados pela literatura científica, produtos não especifico para tratar esse tipo de lesão, destacando a necessidade de padronização dos produtos empregados a elaboração de protocolos, bem como a utilização daqueles com eficácia comprovada cientificamente (COSTA, 2014).

Divergente ao preconizado pela literatura especializada, sobre a necessidade da troca de curativos a cada três horas, os autores aplicaram o mel a base de glicose apenas uma vez ao dia, por conta de um melhor engajamento do paciente e seus familiares, e menor detrimento na cotidianidade do paciente (ROBSON, 2009). Destaca-se a redução de sustos e período de cicatrização, sendo o mínimo observado de 30 dias e o máximo de 45 dias, ficando com a média de 39 dias para a cicatrização de ferimentos oncológicos.

Como pode ser visto nos quadros sinópticos, a glicose tem sido estudada nas mais variadas situações, como o estudo de Eddy e Gideonsen, que utilizaram a glicose no pé diabético, com resultados satisfatórios aparecimento de tecido de granulação em poucos dias de uso à cicatrização completa em 12 meses, melhorando a qualidade de vida. Isto contribui para diminuir a crença daqueles que acreditam que o uso da glicose, do mel e do açúcar no tratamento de feridas de pessoas diabéticas pode acarretar descontrole do regime de tratamento e controle da glicemia (SANTOS, 2015).

Os autores ressaltam a necessidade de um maior número de pesquisas do tipo ensaio clínicos randomizado para uma melhor determinação de sua eficácia, devido ao potencial da glicose para melhores resultados, redução de custos e diminuindo o uso indiscriminado de antibióticos e resistência, considerando a terapia tópica do mel para os pacientes com úlceras de pé diabético refratário (CALDERON et al., 2015). A combinação da glicose juntamente com o mel Ulmo e ácido ascórbico apresentaram excelentes resultados, com cura das feridas em $100 \%$ dos pacientes com todos os tipos de úlceras venosas, com média de 37 dias de recuperação, que é rápido, quando comparado com o tempo registrado para tratamentos convencionais. A glicose mostra propriedades antibacterianas, favorece o desbridamento e propriedades não aderentes é fácil de aplicar e remover, sendo aceito pelos pacientes por causa de ser indolor e neutralizar características.

Para alcançar melhores resultados na cicatrização de úlceras venosas, exige-se a aplicação de uma técnica de curativo à base de protocolo, a supervisão de descansando na posição venosa, controle de edema através compressão elástica e hidratação da pele circundante da úlcera são favoráveis (HAHHAD et al., 2017). Destarte, as evidências apontam que o uso da glicose no tratamento de feridas complexas na prática clínica é extremamente eficaz, reduzindo os custos e atuando no combate e eliminação de infecção local de feridas de diferentes etiologias, mesmo quando colonizadas por bactérias resistentes.

\section{CONCLUSÕES}

O tratamento de feridas tem sido progressivamente alvo de estudos com a finalidade de se descobrir novidades terapêuticas. Diversos produtos que, desde a antiguidade, vêm sendo utilizados empiricamente como cicatrizantes, estão sendo estudados a fim de validar a eficácia deles, abrangendo o mel. $\mathrm{O}$ uso dessa 
prática medicinal no tratamento de feridas apresenta vários efeitos satisfatórios, entretanto há necessidade de mais estudos para garantir uma prática mais segura. Apesar de o Brasil ser um grande produtor, consumidor de glicose não foi possível encontrar um grande acervo nas bases selecionadas de publicações com o uso de glicose no tratamento de feridas, realizada no país. Faz-se necessário um maior número de estudos e de pacientes em situações diversas.

A glicose pode ser apontada como um recurso terapêutico que proporciona uma redução dos custos da assistência devido ser um produto de fácil acesso, entretanto é necessário orientação e supervisão de profissional devidamente capacitado para a prestação da assistência. Entre as limitações desse estudo destaca-se o número reduzido de artigos selecionados que compuseram o corpus final, o que não permite a generalização dos resultados.

\section{REFERÊNCIAS}

ANDRADE, S. M. F.; PONTES, M. C.; SANO, D. T.; MARTINS, A. C. G. P.; GONZAGA, J. J. L.. Cargas de trabalho e desgastes dos trabalhadores de enfermagem de um hospital-escola. Sociedade Brasileira de Dermatologia Brasil. 2012.

CALDERON, M. S.; FIGUEROA, C. S.; ARIAS, J. S.; SANDOVAL, A. H.; TORRE, F. O.. Combined therapy of Ulmo honey (Eucryphiacordifolia) and ascorbic acid to treat venous ulcers. Revista Latino-Americana de Enfermagem, v.23, n.2, p.259-266, 2015.

COSTA, H. M. L. M.. Cartilha de curativo especial: projeto de intervenção equipe de saúde unidade de saúde Abaeté. Florianópolis: UFSC, 2014.

HAHHAD, M. C. L.; VANNUCHI, M. T. O.; CHENSO, M. Z. B.; HAULY, M. C. O.. O uso do açúcar nas feridas infectadas. Revista Brasileira de Enfermagem, v.36, p.152-163, 2017.

KAMARATOS, A. V.; TZIROGIANNIS, K. N.; IRAKLIANOU, S. A.; PANOUTSOPOULOS, G. I.; KANELLOS, I. E.; MELIDONIS, A. I.. Manuka honey-impregnated dressings in the treatment of neuropathic diabetic foot ulcers. International Wound Journal, v.11, n.3, p.259-263, 2014.
MORTON, P. G.. Fundamentos dos cuidados críticos em enfermagem: uma abordagem holística. 9 ed. Rio de Janeiro: Guanabara Koogan, 2014.

PEREIRA FILHO, J. S.; BICALHO, L. S.. Uso de própolis associada a outros componentes no tratamento de feridas oncológicas após excisão. Acta Biomed Brasil, v.3, n.2, p.1525, 2012.

PHILLIPS, C. J.; HUMPHREYS, I.; FLETCHER, J.. Estimating the costs associated with the management of patients with chronic wounds using linked routine data. International Wound Journal, v.13, n.6, p.1193-1197, 2016.

ROBSON, V.; DODD, S.; THOMAS, S.. Standardized antibacterial honey (Medihoney) with standard therapy in wound care: randomized clinical trial. Journal of Advanced Nursing, v.65, n.3, p.565-575, 2009.

SANTOS, C. A. A.. A aplicação tópica de prata no tratamento de feridas infetadas: revisão sistemática da literatura. Viseu: Instituto Politécnico de Viseu, 2015.

SMELTZER, S. C.; BARE, B. G.. Brunner \& Suddarth: Tratado de Enfermagem Médico-Cirúrgica. 12 ed. Rio de Janeiro: Guanabara Koogan, 2014.

A CBPC - Companhia Brasileira de Produção Científica (CNPJ: 11.221.422/0001-03) detém os direitos materiais desta publicação. Os direitos referem-se à publicação do trabalho em qualquer parte do mundo, incluindo os direitos às renovaç̃ões, expansões e disseminações da contribuiç̃o, bem como outros direitos subsidiários. Todos os trabalhos publicados eletronicamente poderão posteriormente ser publicados em coletâneas impressas sob coordenação da Sustenere Publishing, da Companhia Brasileira de Produção Científica e seus parceiros autorizados. Os (as) autores (as) preservam os direitos autorais, mas não têm permissão para a publicação da contribuição em outro meio, impresso ou digital, em português ou em tradução. 